\title{
Trend analysis of plasma insulin level around parturition in relation to parity in Saanen goats ${ }^{1}$
}

\author{
D. Magistrelli*2 and F. Rosi* \\ *University of Milan - Department of Agricultural and Environmental Sciences, via G. Celoria, 2 - 20133 Milan, Italy
}

\begin{abstract}
The present study investigated the effect of parity on plasma insulin level around parturition in Saanen goats. On d $-14,-7,0,3,7,10$, and 14 from parturition, plasma glucose, NEFA, free AA, cortisol, and insulin concentrations were analyzed in 10 primiparous and 10 multiparous goats. At parturition, BW of primiparous goats was about $75 \%$ of that of multiparous ones $(P<$ $0.001)$ and then their milk production was lower than that of multiparous ones $(P<0.001)$. At parturition, glucose increased $(P<0.01)$ in both primiparous and multiparous goats and then decreased $(P<0.01)$ on $\mathrm{d} 3$ of lactation, remaining higher $(P<0.01)$ in primiparous than multiparous goats until the end of the study period. In both groups, free AA decreased $(P<0.01)$ at parturition, returning to prepartum levels $(P<0.01)$ on $\mathrm{d} 3$ of lactation without difference between groups. Only in multiparous goats, plasma NEFA increased at parturition $(P<0.01)$, returning to prepartum levels on $\mathrm{d} 14(P<0.01)$. Changes in glucose and AA could have been caused by cortisol,
\end{abstract}

which increased $(P<0.01)$ at parturition in both primiparous and multiparous goats, returning to prepartum levels $(P<0.01)$ on $\mathrm{d} 7$ of lactation, without difference between the parity groups. In multiparous goats, insulin decreased soon after parturition $(P<0.05)$, remaining at low levels until the end of the study period, whereas in primiparous goats, insulin did not vary until d 14 of lactation, when it decreased $(P<0.05)$ also in this group. Therefore, between $\mathrm{d} 3$ and 14 of lactation, insulin was higher in primiparous than multiparous goats $(P<0.05)$. Only in primiparous goats, at kidding, insulin was negatively correlated to BW $(P<0.01)$, and after parturition it was negatively correlated with milk yield $(P<0.05)$ and plasma NEFA $(P<0.05)$. We hypothesize that higher insulin levels in primiparous Saanen goats, which are still immature at their first breeding season, acted to limit both the mobilization of bodily reserves and the capture of nutrients by the lactating mammary gland, thus providing nutrients for their own physical and physiological development.

Key words: cortisol, glucose, insulin, parity, peripartum, Saanen goats

(C) 2014 American Society of Animal Science. All rights reserved.

J. Anim. Sci. 2014.92:2440-2446 doi:10.2527/jas2013-6993

\section{INTRODUCTION}

The total number of goats in the world has increased by $46 \%$ between 1990 and 2008, enhancing its importance in the livestock sector (Aziz, 2010). Nevertheless, there is a lack of information regarding factors that affect whole body metabolism during pregnancy and lactation in the goat.

During pregnancy and lactation, the endocrine system provides optimal conditions for the development of the fetus and of the mammary gland and its func-

\footnotetext{
${ }^{1}$ The authors want to thank Davide De Angeli, Marco Misitano, Luca Rapetti, Alberto Tamburini, Pietro Parma, and Luca Malagutti for the help in livestock management, blood sampling, and statistical analysis.

${ }^{2}$ Corresponding author: damiano.magistrelli@guest.unimi.it

Received August 5, 2013.

Accepted April 4, 2014.
}

tion (Chávez et al., 2009; Skotnicka et al., 2011). The transition from pregnancy to lactation involves variation in circulating concentrations of metabolites and hormones (Iriadam, 2007; Chávez et al., 2009). Energy requirement by the gravid uterus and then by the lactating mammary gland greatly increases and could be not covered by dietary intake. Homeoretic adaptation to this condition starts within few days from parturition by enhancing bodily reserves mobilization and liver gluconeogenesis and by decreasing glucose utilization by peripheral tissue (Comline and Silver, 1972; Bell, 1995; Sadjadian et al., 2013). The interplay of factors regulating these metabolic adjustments in goats is complicated by parity. Doelings reach puberty by 6 to 8 mo of age and, in modern livestock production systems, are usually bred at 7 to 9 mo of age, when BW is about $60 \%$ of the adult weight. This practice is required due 
to the seasonality in their reproductive activity. After a 5-mo period of gestation, primiparous goats weigh about $75 \%$ of the adult goat (Shelton, 1978). Physical and physiological maturation is still incomplete at the time of first kidding and it may result in a different endocrine background between primiparous and multiparous goats. This topic was first approached by Bonnet et al. (2005), who reported leptinemia variations throughout the pregnancy-lactation cycle in goats, in relation to parity, but no such study has been developed for other metabolic hormones, including insulin, despite its role in the regulation of energy partitioning, as described by Rosi et al. (2009). The aim of this study was to investigate the effect of parity on plasma insulin levels in periparturient goats. Energy partitioning during the transition from late pregnancy to early lactation was examined.

\section{MATERIALS AND METHODS}

\section{Animals and Diets}

Ten primiparous and 10 multiparous (parity $=3$ ) Saanen goats (Capra hircus) were studied for $14 \mathrm{~d}$ before and $14 \mathrm{~d}$ after parturition. The animals used in the trial were reared in accordance with European Union guidelines (directive 86/609/CEE) and Italian legislation (DL 116, 1992, and DL 473, 1993) and considered clinically healthy by the local sanitary authorities. All the primiparous goats were about $1 \mathrm{yr}$ old and multiparous goats were about 3 yr old. Goats were not synchronized and all the deliveries were recorded over a period of $2 \mathrm{wk}$. Before parturition, goats were housed in 4 pens ( 2 pens per parity). Soon after parturition, each mother was moved to 1 of 4 new pens reserved to goats of the same parity. All the pens were allotted in the same room, under identical environmental conditions. Goats were fed a total mixed ration ad libitum. Before parturition, diet consisted of $30.0 \%$ ryegrass hay, $30.0 \%$ dehydrated alfalfa hay, $17.0 \%$ maize meal, $5.0 \%$ wheat straw, $3.0 \%$ soybean meal, $6.7 \%$ Bio-Chlor rumen fermentation enhancer (Arm \& Hammer Animal Nutrition, Princeton, NJ), and 8.3\% mineral/ vitamin supplement. Soon after parturition, all goats were fed a diet consisting of $41.8 \%$ dehydrated alfalfa hay, $10.5 \%$ wheat straw, $12.1 \%$ steam-flaked maize, $6.0 \%$ maize meal, $6.0 \%$ steam-extruded barley, $7.9 \%$ soybean meal, $6.0 \%$ dried sugar beet pulp, 3.1\% sugarcane molasses, $3.7 \%$ mineral/vitamin supplement, and $2.9 \%$ Megalac rumen-protected fats (Volac International Ltd, Orwell, UK). Diets were formulated as described by Pulina and Cannas (2008), with proximate analysis in Table 1. The ration was administered twice per day (0900 and $1630 \mathrm{~h}$ ). Before administration, leftovers were removed from the trough. During the entire experimental period, goats had free access to fresh water.
Table 1. Analysis of the total mixed rations (TMR) administered before (TMR prepartum) and after (TMR postpartum) parturition to the periparturient goats

\begin{tabular}{lcc}
\hline \hline Item & TMR prepartum & TMR postpartum \\
\hline $\mathrm{DM}, \%$ & 88.5 & 88.5 \\
CP, \% DM & 14.7 & 15.9 \\
Ether extract, \% DM & 2.76 & 4.87 \\
NDF, \% DM & 42.2 & 33.0 \\
ADF, \% DM & 29.9 & 22.8 \\
ADL, \% DM & 5.49 & 5.48 \\
Starch, \% DM & 18.2 & 19.1 \\
Minerals, \% DM & 9.80 & 10.4 \\
ME, MJ/kg DM & 9.38 & 10.4 \\
\hline
\end{tabular}

Soon after birth, kids were separated from their mothers and all the goats were subjected to double daily machine milking (0730 and $1800 \mathrm{~h}$ ) until the end of the study period.

\section{Measures and Samples}

On d 14 and 7 before parturition and on d 3, 7, 10, and 14 of lactation, mean DMI per group was recorded. On the same days, jugular vein blood samples were taken before the meal. Moreover, a blood sample was taken $1 \mathrm{~h}$ after delivery. Blood $(5 \mathrm{~mL})$ was withdrawn using vacuum tubes containing $\mathrm{K}_{3}$ EDTA and aprotinin $(50 \mu \mathrm{L} /$ $\mathrm{mL}$ Trasylol; Bayer, Leverkusen, Germany) and was immediately centrifuged at $2,500 \times \mathrm{g}$ for $15 \mathrm{~min}$ at $10^{\circ} \mathrm{C}$. Plasma obtained was stored at $-20^{\circ} \mathrm{C}$, pending analysis.

On kidding day, litter size for each goat, kid BW, and whole litter BW were recorded. On the same day, each goat was weighed after complete expulsion of the placenta and fetal annexes.

On d $0,3,7,10$, and 14 of lactation, daily milk yield was recorded.

\section{Plasma Analysis}

Plasma was analyzed for glucose by the GOD-POD (glucose-oxidase/peroxidase) method (Giesse Diagnostics Srl, Rome, Italy), for NEFA by the ACS-ACOD-MEHA (acyl-CoA-synthetase/acyl-CoA-oxidase/3-methylN-ethyl-N- $\beta$-hydroxyethyl-aniline) method (Waco Chemicals GmbH, Neuss, Germany), for free AA by the method described by Goodwin (1968), for cortisol using a commercial ELISA kit (ELISA Cortisol; DRG International Inc., Mountainside, NJ), and for insulin level using a commercial RIA kit (Insik 5; DiaSorin Spa, Saluggia, VC, Italy). This latter protocol, using antibodies directed to human insulin, was validated for goat plasma by 1) parallelism test - serial dilutions of goat plasma in assay buffer produced curves parallel to the standard curveand 2) recovery test-known amounts of standard solutions added to goat plasma produced proportional 
Table 2. Litter size per goat, kid BW, litter BW, and BW of primiparous $(n=10)$ and multiparous $(n=10)$ goats recorded on parturition day. Data are presented as mean value $\pm \mathrm{SE}$

\begin{tabular}{lccccc}
\hline \hline & Litter size, ${ }^{1}$ no. & Kid BW, ${ }^{2} \mathrm{~kg}$ & Litter BW, ${ }^{2} \mathrm{~kg}$ & Goat BW, ${ }^{2} \mathrm{~kg}$ & $\mathrm{Litter} \mathrm{BW},{ }^{2} \%$ goat BW \\
\hline Primiparous & $2.10 \pm 0.28$ & $3.63 \pm 0.14$ & $7.62 \pm 0.81$ & $50.3 \pm 0.79$ & $15.2 \pm 1.55$ \\
Multiparous & $2.50 \pm 0.27$ & $3.43 \pm 0.16$ & $8.58 \pm 0.25$ & $66.2 \pm 0.25$ & $13.0 \pm 0.25$ \\
$P$-value & $>0.05$ & $>0.05$ & $>0.05$ & $<0.001$ & $>0.05$ \\
\hline
\end{tabular}

${ }^{1}$ Analyzed by $\chi^{2}$ test with Yates' correction.

${ }^{2}$ Analyzed by ANOVA.

increases in the level of insulin. All the parameters listed above were determined in duplicate. The intra-assay coefficient of variability for $n=20$ was 2.2, 2.7, 8.1, and $6.6 \%$ for glucose, NEFA, cortisol, and insulin, respectively. The interassay coefficient of variability was 2.1 , $2.7,6.6$, and $6.2 \%$ for glucose, NEFA, cortisol, and insulin, respectively. Analytical sensitivity was found to be $6.9 \mathrm{nmol} / \mathrm{L}$ for cortisol and $20.8 \mathrm{pmol} / \mathrm{L}$ for insulin.

\section{Statistical Analysis}

Data were analyzed by PROC MIXED for repeated measures, with Bonferroni's adjustment for multiple comparisons, considering parity, time-distance from parturition, and their interactions as fixed effects. The model used was

$$
Y_{i j}=\mu+P_{i}+T_{j}+(P \times T)_{i j}+e_{i j},
$$

in which $Y_{i j}$ is the observed value of the dependent variable determined from a sample taken from each animal, $\mu$ is the overall mean, $P_{i}$ is the fixed effect of the $i$ th parity, $T_{j}$ is the fixed effect of the $j$ th day of distance from parturition, $(P \times T)_{i j}$ is the interaction between parity and time-distance from parturition, and $e_{i j}$ is the residual error. The effect of litter size was not significant, so it was not included in the statistical model.

Measures recorded just on parturition day (kid BW, litter BW, and goat BW) were analyzed by ANOVA (PROC GLM; SAS Inst. Inc., Cary, NC) or by the $\chi^{2}$ test (litter size) with Yates' correction (Petrie and Watson, 2006).

Correlations were computed using Pearson's correlation analysis. The limit of significance was set at $P \leq$ 0.05 . Results are presented as mean $\pm \mathrm{SE}$.

\section{RESULTS}

\section{Mean DMI, Litter Size, Kid BW, Goat BW, and Milk Yield}

Dry matter intake, calculated as mean per group, was lower for primiparous goats compared to multiparous ones both before parturition ( $1.80 \pm 0.02$ vs. $2.08 \pm$ $0.03 \mathrm{~kg} / \mathrm{d} \cdot$ animal for primiparous and multiparous goats, respectively; $P<0.001)$ and after parturition $(1.97 \pm$ 0.04 vs. $2.31 \pm 0.08 \mathrm{~kg} / \mathrm{d} \cdot \operatorname{animal} ; P<0.01)$. Mean DM increased after parturition for both primiparous $(P<$ $0.05)$ and multiparous goats $(P<0.05)$.

Litter size, kid BW, and litter BW at parturition did not differ $(P>0.05)$ between the groups (Table 2). Primiparous dams weighed less $(P<0.001)$ than multiparous goats (Table 2).

Milk yield was greater $(P<0.001)$ for multiparous goats than primiparous ones over the entire study period (Fig. 1).

\section{Plasma Analysis}

Before parturition, no difference was observed in the levels of plasma metabolites $(P>0.05)$ between primiparous and multiparous goats (Table 3). Plasma glucose level increased $(P<0.01)$ in both primiparous and multiparous goats at parturition and decreased $(P<$ $0.01)$ on $\mathrm{d} 3$ of lactation. Plasma glucose concentration remained greater $(P<0.01)$ from d 3 through 14 in the primiparous goats by comparison to the multiparous dams (Table 3). The postpartum concentrations of plasma glucose were greater in primiparous dams $(P<0.01)$ when compared to prepartum concentrations (Table 3 ). Plasma glucose was negatively correlated to milk yield

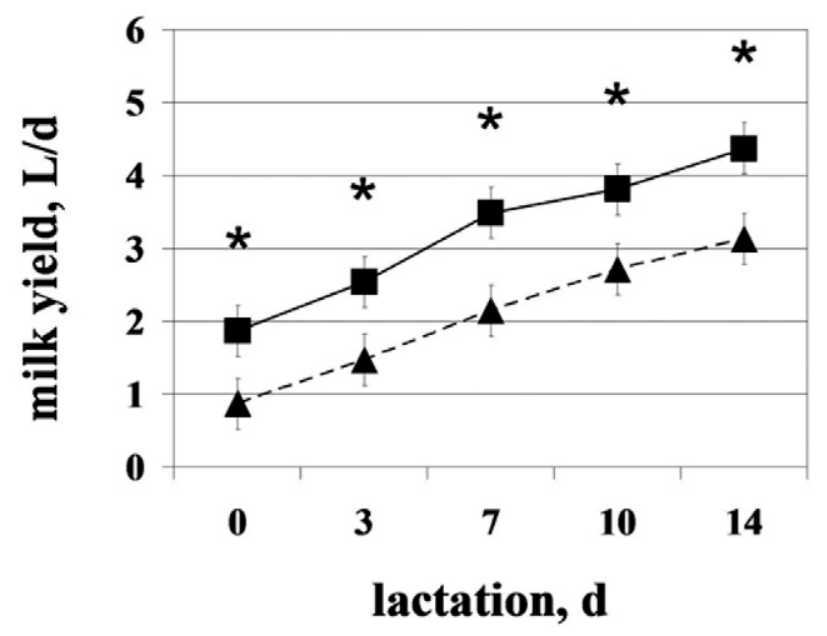

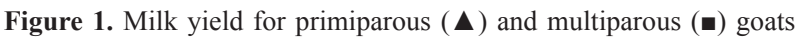
during the first $14 \mathrm{~d}$ of lactation. Bars indicate SE. The asterisk indicates differences between groups, with $P<0.001$. 
Table 3. Analysis of plasma glucose, NEFA, free AA, cortisol, and insulin in primiparous $(n=10)$ and multiparous $(n=10)$ goats, around parturition. Data are presented as mean value $\pm \mathrm{SE}^{1}$

\begin{tabular}{|c|c|c|c|c|c|c|c|}
\hline \multirow[b]{2}{*}{ Item } & \multicolumn{7}{|c|}{ Time-distance from parturition, $\mathrm{d}$} \\
\hline & -14 & -7 & 0 & 3 & 7 & 10 & 14 \\
\hline \multicolumn{8}{|l|}{ Glucose, $\mathrm{mmol} / \mathrm{L}$} \\
\hline Primiparous & $3.12 \pm 0.13^{\mathrm{A}}$ & $3.06 \pm 0.07^{\mathrm{A}}$ & $6.78 \pm 1.23^{\mathrm{C}}$ & $3.36 \pm 0.17^{\mathrm{B}}$ & $3.42 \pm 0.10^{\mathrm{B}}$ & $3.68 \pm 0.11^{\mathrm{B}}$ & $3.56 \pm 0.10^{\mathrm{B}}$ \\
\hline Multiparous & $2.98 \pm 0.10^{\mathrm{A}}$ & $2.94 \pm 0.06^{\mathrm{A}}$ & $6.77 \pm 0.52^{\mathrm{C}}$ & $2.51 \pm 0.13^{\mathrm{A}}$ & $2.79 \pm 0.11^{\mathrm{A}}$ & $2.90 \pm 0.15^{\mathrm{A}}$ & $3.12 \pm 0.13^{\mathrm{A}}$ \\
\hline \multicolumn{8}{|l|}{$\mathrm{NEFA}, \mathrm{mmol} / \mathrm{L}$} \\
\hline Primiparous & $0.39 \pm 0.10^{\mathrm{B}}$ & $0.41 \pm 0.08^{\mathrm{B}}$ & $0.47 \pm 0.07^{\mathrm{B}}$ & $0.46 \pm 0.05^{\mathrm{B}}$ & $0.42 \pm 0.06^{\mathrm{B}}$ & $0.33 \pm 0.03^{\mathrm{B}}$ & $0.18 \pm 0.01^{\mathrm{A}}$ \\
\hline Primiparous & $3.46 \pm 0.15^{\mathrm{B}}$ & $3.32 \pm 0.18^{\mathrm{B}}$ & $2.42 \pm 0.14^{\mathrm{A}}$ & $3.62 \pm 0.22^{\mathrm{B}}$ & $3.65 \pm 0.14^{\mathrm{B}}$ & $3.83 \pm 0.15^{\mathrm{B}}$ & $3.83 \pm 0.25^{\mathrm{B}}$ \\
\hline Multiparous & $3.42 \pm 0.15^{\mathrm{B}}$ & $3.07 \pm 0.11^{\mathrm{B}}$ & $2.27 \pm 0.15^{\mathrm{A}}$ & $3.84 \pm 0.16^{\mathrm{B}}$ & $3.33 \pm 0.10^{\mathrm{B}}$ & $3.46 \pm 0.18^{\mathrm{B}}$ & $3.74 \pm 0.26^{\mathrm{B}}$ \\
\hline \multicolumn{8}{|l|}{ Cortisol, nmol/L } \\
\hline Primiparous & $43.4 \pm 7.81^{\mathrm{A}}$ & $35.7 \pm 6.35^{\mathrm{A}}$ & $92.7 \pm 15.3^{\mathrm{B}}$ & $73.8 \pm 8.53^{\mathrm{B}}$ & $35.4 \pm 8.15^{\mathrm{A}}$ & $23.9 \pm 3.76^{\mathrm{A}}$ & $22.7 \pm 3.21^{\mathrm{A}}$ \\
\hline Multiparous & $39.3 \pm 5.34^{\mathrm{A}}$ & $36.3 \pm 3.98^{\mathrm{A}}$ & $94.4 \pm 17.3^{\mathrm{B}}$ & $83.4 \pm 10.5^{\mathrm{B}}$ & $39.5 \pm 9.14^{\mathrm{A}}$ & $28.5 \pm 6.67^{\mathrm{A}}$ & $22.2 \pm 0.89^{\mathrm{A}}$ \\
\hline
\end{tabular}

${ }^{1}$ Within each parameter, values bearing unlike letters are statistically different. Uppercase letters are used for $P \leq 0.01$ and lowercase letters are used for $P \leq 0.05$.

in both primiparous $(r=-0.49, n=50, P<0.01)$ and multiparous goats $(r=-0.64, n=50, P<0.01)$.

In primiparous goats, plasma NEFA concentrations did not vary until d 14 of lactation, when they halved $(P<0.01)$. By contrast, plasma NEFA concentration of multiparous goats greatly increased $(P<0.01)$ at parturition and returned to the levels observed before parturition $(P<0.01)$ on d 14 of lactation (Table 3). Starting from parturition until the end of the study period, plasma NEFA were higher $(P<0.01)$ in multiparous goats than primiparous ones (Table 3 ). On parturition day, plasma NEFA concentration was positively correlated with litter size $(r=0.71, n=10, P<0.01$ and $r=0.79, n=10$, $P<0.01$ for primiparous and multiparous goats, respectively) and litter BW ( $r=0.58, n=10, P<0.05$ and $r=$ $0.64, n=10, P<0.05)$ in both parity groups.

On the day of parturition, plasma AA decreased $(P<$ $0.01)$ in both groups and rapidly returned to the levels observed before parturition $(P<0.01)$, without difference between primiparous and multiparous goats (Table 3 ).

On parturition day, plasma cortisol increased $(P<0.01)$ in both primiparous and multiparous goats and returned $(P<$ $0.01)$ to prepartum levels $7 \mathrm{~d}$ postpartum, without difference $(P>0.05)$ between the experimental groups (Table 3$)$.

Before parturition, plasma insulin was not different between groups $(P>0.05)$. In primiparous goats, insulin did not vary until d 14 postpartum, when it abruptly decreased $(P<0.05$; Table 3$)$. By contrast, in multiparous goats $3 \mathrm{~d}$ after parturition, plasma insulin decreased by $40 \%(P<0.05)$ and then slightly increased $(P=0.10)$ in the following days, reaching the level observed in primiparous goats (Table 3$)$. A significant interaction $(P<0.05)$ between parity and time-distance from parturition $(\boldsymbol{P} \times \boldsymbol{T})$ was observed for insulin. Before parturition, plasma insulin and NEFA were negatively correlated in both primiparous $(r=-0.57, n=20, P<0.01)$ and multiparous $(r=$ $-0.52, n=20, P<0.05$ ) goats, but after parturition, insulin and NEFA were negatively correlated only in primiparous goats $(r=-0.30, n=50, P<0.05)$. In primiparous goats at kidding, plasma insulin level was negatively correlated to BW $(r=-0.79, n=10, P<0.01)$. In primiparous goats, plasma insulin was negatively correlated with milk yield $(r=-0.28, n=50, P<0.05)$, whereas no correlation between plasma insulin and milk yield was observed for multiparous goats at early lactation.

\section{DISCUSSION}

\section{Mean DMI, Litter Size, Kid BW, Goat BW, and Milk Yield}

Contrarily to Chávez et al. (2009), who did not observe variations in DMI after the transition from late pregnancy to early lactation in Nubian goats, we observed an increase of mean DMI after parturition in both primiparous and multiparous goats. This is typical for cattle and ewes, for which late pregnancy is characterized by a decline in feed intake caused by compression of the rumen by the growing fetus (Forbes, 1970). Mean DMI was lower for primiparous than multiparous goats possibly due to blunted development of the digestive tract, as suggested by Goetsch et al. (2001). Although BW of primiparous goats was about $75 \%$ of that of multiparous ones in accordance with Shelton (1978), DMI of primiparous goats was about $85 \%$ of that recorded for multiparous ones. We deduce that, relative to BW, DMI was greater for primiparous than multiparous goats, 
as possible consequence of the fact that dietary requirements of primiparous goats included a portion for weight gain (to reach the adult weight) in addition to those for maintenance and development of the fetuses during late pregnancy or those for maintenance and milk synthesis during early lactation (Pulina and Cannas, 2008).

Saanen goats give birth to $1.34 \pm 0.52$ and $1.46 \pm$ 0.58 kids for primiparous and multiparous goats, respectively (Mellado et al., 2011). We report a greater number of kids per dam that appears not to have affected fetus development. Normal BW at birth indicates that the experimental animals were in optimal conditions throughout gestation (Amoah et al., 1996).

In the multiparous group there was a greater number of goats that gave birth to triplets of kids in comparison to the primiparous group, where just 1 goat gave birth to a triplet. Anyway, in both groups, litter size ranged between 1 and 4 . For its variability, litter size was not different between groups.

Data on litter size, kid BW, and milk yield prove that the Saanen goat is one of the highest milk-producing goat breeds and has a high reproductive yield (Sadjadian et al., 2013).

\section{Plasma Metabolites}

As consequence of their productive and reproductive capacity, periparturient Saanen dairy goats are considered to be in negative energy balance (Sadjadian et al., 2013). The analysis of plasma metabolites (in particular, the low levels of glucose and the high levels of NEFA herein reported) confirms the occurrence of negative energy balance in the goats of the present study.

Plasma glucose levels are consistent to those observed by Pinotti et al. (2008), who analyzed the plasma of multiparous periparturient Saanen goats collected before the first meal of the day, as we did. Similar values were also observed in preprandial plasma of primiparous goats of different breeds during the first week after parturition (Anwar et al., 2012).

As previously reported (Sadjadian et al., 2013), plasma glucose sharply increased on parturition day. This is similar to ewes, whereby pronounced hyperglycemia is caused by cortisol release during the terminal stages of labor (Comline and Silver, 1972). The release of cortisol is known to produce an increase in blood glucose, both stimulating glycogenolysis in the liver and rising gluconeogenesis from nonglycidic precursors (McDowell, 1983). This latter effect could also justify the decrease of plasma AA observed on parturition day in both the primiparous and multiparous goats of the present study.

Soon after parturition, plasma glucose decreased in both the experimental groups but remained at higher levels in primiparous than multiparous goats. Glucose is the primary nutrient for milk synthesis. The largest part of circulating glucose is used by the lactating mammary gland for lactose production (Bell and Bauman, 1983), as also confirmed by the negative correlation between milk yield and plasma glucose level. The lower milk yield by primiparous goats, due to incomplete development of the mammary gland, resulted in a lower mammary glucose uptake that was reflected by greater systemic glucose level at the start of lactation. A similar result is observed in dairy cows (Janovick et al., 2011).

Plasma NEFA levels are consistent to those observed by Pinotti et al. (2008) in multiparous periparturient Saanen goats. At parturition, plasma NEFA concentration greatly increased in multiparous goats. After parturition, plasma NEFA concentrations were higher in multiparous than primiparous goats. A similar result is observed in dairy cows (Wathes et al., 2007). This was possibly due to the fact that in the multiparous group there was a greater number of goats that gave birth to triplets of kids in comparison to the primiparous group. A positive relationship between plasma NEFA and litter size was observed in ewes and goats (Morris and Kenyon, 2004; Laporte-Broux et al., 2011). In the present study, plasma NEFA concentration and litter size were positively correlated on the day of parturition. We suppose, therefore, that the higher concentration of NEFA in multiparous goats in comparison to primiparous ones could also be consequence of higher mobilization of bodily energy reserves in multiparous goats to support a higher requirement for fetuses in late gestation and a higher requirement for milk production, at early lactation (Chávez et al., 2009). Plasma NEFA concentrations greater than $0.7 \mathrm{mmol} / \mathrm{L}$ in goats suggest toxemia (D'Angelo et al., 2005). In our study NEFA levels were always below the toxemic limit, with the exception of that observed on parturition day in multiparous goats, which anyway rapidly decreased, returning to the levels observed before parturition, on d 14 postpartum (Table 3).

\section{Plasma Insulin}

The analysis of plasma insulin levels was characterized by a wide variability, which could have hidden significant variations, particularly in primiparous goats. Nevertheless, plasma insulin profile was different between primiparous and multiparous goats. The higher concentration of glucose in the plasma of primiparous goats could have been responsible for the higher plasma insulin level in these animals in the early postpartum, when plasma glucose was highly correlated to insulin. Anyway, as evidenced by the significant interaction $(P \times T)$ here reported, the time pattern of plasma insulin was different between primiparous and multiparous goats. This difference in the pattern of plasma insulin 
between primiparous and multiparous goats around parturition represents the striking result obtained in the present study. In dairy cows, plasma insulin levels start to decrease before parturition and the lowest concentrations are found at calving and then they rise soon after and are fully recovered $30 \mathrm{~d}$ postpartum, without differences between primiparous and multiparous subjects (Meikle et al., 2004). Adrien et al. (2012) also reported a decrease in plasma insulin concentration at calving in both primiparous and multiparous dairy cows and considered this decrease as a metabolic adaptation to cope with the energy demands of lactation. According to this, one could hypothesize that in dairy cows lactational status per se influences plasma insulin levels, whereas in lactating goats parity as well is involved in the control of insulinemia. As reported above accordingly with other authors, periparturient goats are considered to be in negative energy balance, due to the high requirements of nutrients for rapid fetal growth during late pregnancy and for milk synthesis during early lactation (Bonnet et al., 2005; Sadjadian et al., 2013). This negative energy balance leads periparturient goats to increase lipid mobilization from adipose tissue to meet energy demand, which could not be covered by dietary intake (Chávez et al., 2009). In the present study, plasma NEFA concentration at parturition greatly increased only in multiparous goats and remained at high levels during the first $10 \mathrm{~d}$ of lactation, whereas in primiparous goats plasma NEFA did not vary during the transition from late pregnancy to early lactation. This result indicates that our goats were in negative energy balance at the end of pregnancy and this negative energy balance increased at the beginning of lactation only in multiparous goats. This difference can be explained by the different milk production between groups. Anyway, in primiparous goats, the negative correlation between insulin and NEFA suggests the role of insulin in the reduction of lipomobilization at the beginning of lactation. To justify this latter statement, it is important to consider that (due to the seasonality of the reproductive activity) at the time of first kidding goats are less mature than at the time of the following ones and so they need nutrients also for their own physical and physiological development (Shelton, 1978; Wathes et al., 2007). It is possible to hypothesize, therefore, that the higher levels of plasma insulin observed in primiparous goats compared to the multiparous ones soon after parturition acted as a metabolic strategy to limit both the mobilization of bodily reserves and the capture of nutrients by the lactating mammary gland, thus providing nutrients for whole body growth. This hypothesis is supported also by the negative correlation observed between plasma insulin level and BW and between plasma insulin level and milk yield in primiparous goats. Moreover, our latter hypothesis may contribute to explain previous results reported for primiparous goats, which, despite lipomobilization and contrarily to multiparous goats, do not lose BW during the first month of lactation (Dunshea et al., 1989).

\section{Conclusion}

This study evaluated the pattern of peripartum insulin secretion to parity in Saanen goats. The present study suggests that parity has a key role in the endocrinology of lactation. Contrary to what observed in multiparous goats, in fact, plasma insulin level does not decrease in primiparous goats at the beginning of lactation, a period characterized by an abrupt increase in the requirement of nutrients by the mammary gland. As a consequence of this result, we advance the hypothesis that primiparous goats (which are immature, due to the seasonality of the reproductive activity) limit mobilization of body reserves for lactation as a mechanism to conserve nutrients to continued body growth. These results may be used to better design diets and management schemes for the late gestating and early lactating goat.

\section{LITERATURE CITED}

Adrien, M. L., D. A. Mattiauda, V. Artegoitia, M. Carriquiry, G. Motta, O. Bentancur, and A. Meikle. 2012. Nutritional regulation of body condition score at the initiation of the transition period in primiparous and multiparous dairy cows under grazing conditions: Milk production, resumption of postpartum ovarian cyclicity and metabolic parameters. Animal 6:292-299.

Amoah, E. A., S. Gelaye, P. Guthrie, and C. E. Rexroad Jr. 1996. Breeding season and aspects of reproduction of female goats. J. Anim. Sci. 74:723-728.

Anwar, M. M., T. A. Ramadan, and T. A. Taha. 2012. Serum metabolites, milk yield, and physiological responses during the first week after kidding in Anglo-Nubian, Angora, Baladi, and Damascus goats under subtropical conditions. J. Anim. Sci. 90:4795-4806.

Aziz, M. A. 2010. Present status of the world goat populations and their productivity. Lohmann Inf. 45:42-52.

Bell, A. W. 1995. Regulation of organic nutrient metabolism during transition from late pregnancy to early lactation. J. Anim. Sci. 73:2804-2819.

Bell, A. W., and D. E. Bauman. 1983. Adaptation of glucose metabolism during pregnancy and lactation. J. Mammary Gland Biol. Neoplasia 2:265-278.

Bonnet, M., C. Delavaud, J. Rouel, and Y. Chilliard. 2005. Pregnancy increases plasma leptin in nulliparous but not primiparous goats while lactation depresses it. Domest. Anim. Endocrinol. 28:216-223.

Chávez, J., G. Bernal, J. A. Rodríguez, E. Díaz, A. Aguilera, T. Reis de Souza, K. Mark, and M. Cárdenas. 2009. Influence of pregnancy and lactation on glucose metabolism of Nubian goats. Trop. Subtrop. Agroecosyst. 11:225-232.

Comline, R. S., and M. Silver. 1972. The composition of foetal and maternal blood during parturition in the ewe. J. Physiol. 222:233-256.

D’Angelo, A., E. Trevisi, A. Gaviraghi, S. Comazzi, L. Noè, G. Bertoni, and G. F. Greppi. 2005. Blood inflammatory indices and liver functionality in dairy goats around parturition. In: Proc. 13th Int. Congr. Mediterr. Fed. Health Prod. Rumin. (Fe. Me.S.P.Rum.), Bari, Italy. p. 216-220. 
Dunshea, F. R., A. W. Bell, and T. E. Trigg. 1989. Relations between plasma non-esterified fatty acid metabolism and body fat mobilization in primiparous lactating goats. Br. J. Nutr. 62:51-61.

Forbes, J. M. 1970. Voluntary food intake of pregnant ewes. J. Anim. Sci. 31:1222-1227.

Goetsch, A. L., G. Detweiler, T. Sahlu, R. Puchala, and L. J. Dawson. 2001. Dairy goat performance with different dietary concentrate levels in late lactation. Small Rumin. Res. 41:117-125.

Goodwin, J. F. 1968. The colorimetric estimation of plasma amino nitrogen with DNFB. Clin. Chem. 14:1080-1090.

Iriadam, M. 2007. Variation in certain haematological and biochemical parameters during the peri-partum period in Kilis does. Small Rumin. Res. 73:54-57.

Janovick, N. A., Y. R. Boisclair, and J. K. Drackley. 2011. Prepartum dietary energy intake affects metabolism and health during the periparturient period in primiparous and multiparous Holstein cows. J. Dairy Sci. 94:1385-1400.

Laporte-Broux, B., S. Roussel, A. A. Ponter, J. Perault, P. ChavattePalmer, and C. Duvaux-Ponter. 2011. Short-term effects of maternal feed restriction during pregnancy on goat kid morphology, metabolism, and behavior. J. Anim. Sci. 89:2154-2163

McDowell, G. H. 1983. Hormonal control of glucose homoeostasis in ruminants. Proc. Nutr. Soc. 42:149-167.

Meikle, A., M. Kulcsar, Y. Chilliard, H. Febel, C. Delavaud, D. Cavestany, and P. Chilibroste. 2004. Effects of parity and body condition at parturition on endocrine and reproductive parameters of the cow. Reproduction 127:727-737.

Mellado, M., C. A. Meza-Herrera, J. R. Arévalo, M. A. De SantiagoMiramontes, A. Rodríguez, J. R. Luna-Orozco, and F. G. VelizDeras. 2011. Relationship between litter birthweight and litter size in five goat genotypes. Anim. Prod. Sci. 51:144-149.
Morris, S. T., and P. R. Kenyon. 2004. The effect of litter size and sward height on ewe and lamb performance. N. Z. J. Agric. Res. 47:275-286.

Petrie, A., and P. Watson. 2006. Statistics for veterinary and animal science. 2nd ed. Blackwell Publishing, Oxford, UK.

Pinotti, L., A. Campagnoli, F. D’Ambrosio, F. Susca, M. Innocenti, R. Rebucci, E. Fusi, F. Cheli, G. Savoini, V. Dell'Orto, and A. Baldi. 2008. Rumen-protected choline and vitamin E supplementation in periparturient dairy goats: Effects on milk production and folate, vitamin B12 and vitamin E status. Animal 2:1019-1027.

Pulina, G., and A. Cannas. 2008. Dairy goats: Nutrition and feeding. CAB Int., Wallingford, UK.

Rosi, F., A. A. Aufy, and D. Magistrelli. 2009. Diet influences the content of bioactive peptides in goat milk. J. Endocrinol. Invest. 32:486-490.

Sadjadian, R., H. A. Seifi, M. Mohri, A. A. Naserian, and N. Farzaneh. 2013. Variations of energy biochemical metabolites in periparturient dairy Saanen goats. Comp. Clin. Pathol. 22:449-456.

Shelton, M. 1978. Reproduction and breeding of goats. J. Dairy Sci. 61:994-1010.

Skotnicka, E., Z. Muszczynski, and M. Suska. 2011. Effect of the periparturient period on serum lipid and cholesterol lipoprotein concentrations in goats (Capra hircus). Acta Vet. Hung. 59:445-454.

Wathes, D. C., Z. Cheng, N. Bourne, V. J. Taylor, M. P. Coffey, and S. Brotherstone. 2007. Differences between primiparous and multiparous dairy cows in the inter-relationships between metabolic traits, milk yield and body condition score in the periparturient period. Domest. Anim. Endocrinol. 33:203-225. 